\title{
Analysis of Intertextuality in English News Headlines
}

\author{
Qin Xie \\ Shanxi Normal University, China
}

\begin{abstract}
Nowadays, English news plays an increasingly important role in cultural communication between Chinese and the western as a media. Headline tends to be the most eye-catching news text as the punch line, and intertextuality is usually one of its characteristics. Based on the descriptions of the main manifestations of intertextuality in English news headlines and the analyses of the relationship between the intertextuality and the functions of news headlines from the pragmatic perspective, the author thinks intertextuality can better realize the communicative function of news discourse by enhancing the sustainability of the headline. Meanwhile, the study of intertextuality provides some revelations to the production of the foreign English news headlines.
\end{abstract}

Index Terms - intertextuality, English news headlines, pragmatic function

\section{INTRODUCTION}

Intertextuality is a prominent feature of news discourse, and its theory is widely applied in the critical analysis of news discourse. Although the headline is an important part of English news discourse, there are a few existing articles on their intertextual analysis. Based on the descriptions of the main manifestations of intertextuality in English news headlines and the analyses of the relationship between the intertextuality and the functions of news headlines from the pragmatic perspective, the author thinks intertextuality can better realize the communicative function in news discourse by enhancing the sustainability of the headline. Meanwhile, the analysis of intertextuality provides some englithtenment for the production of foreign English news headlines.

\section{ANALYSIS OF INTERTEXTUALITY AND THE INTERTEXTUALITY OF NEWS DISCOURSE}

The intertextuality stems from the Latin Intertexto, which means intermingle while weaving. In the late of 1960s, Kristeva put forward the term "intertextuality" firstly in her early work. She (1980) pointed out that "the construction of any text is regarded as a mosaic of citations; every text is absorbing and transforming from the other one." (p. 36-37) In her point view of intertextuality, there are two axes in texts, which include the horizontal axis and the vertical axis. The former connects the author and reader of the same one text. The latter establishes a connection between the text and other texts. And these two axes are connected by the shared codes. The discourse is interrelated and interdependent, forming an infinite and open network.

The intertextual theory developed from Bakhtin's theory of dialogue. With the further enrichment and development of Barthes and Genette and so on, this theory gradually matured and became an important text theory of contemporary western postmodernism. "Intertextuality takes any culture into the language chain of authors, works, readers, and society. It is possible to fully understand the intertextual relationships of the text, which not only has the significance of methodology, but also become the cornerstone of western literary theory in the 20th century." (Jiao Shumin \& Lu Puling, 2009, p. 102)

Intertextuality research was limited to literary critique for a long time, but recently it received widespread attention in discourse analysis. Especially critical linguists who regard news discourse as the most major analysis objects pay more and more attention to it. The implicit even conflicting ideologies and power relationships in news discourse can be revealed through the analysis of intertextual relationships. Fowler (1991) believes that allusion has the function of arousing the reader's specific paradigm knowledge. The values associated with the paradigm are presented at the same time by quoting intertext. Goatly (2000) sees the process of production of news as an intercultural chain, and journalists can distort the long intercultural chain in the news consciously or unconsciously. Van Dijk (2003) points out that quotes or quasi-quotes are closer to the truth, which not only can make reporting more vivid and reliable, but also protect journalists from defamation.

In China, the intertextual research of news discourse mainly focuses on the reported speech. Xin Bin (2005) thinks that the quotation in news discourse is seemingly objective and fair, In fact, the reporter often involved in affecting readers' understanding of speech with his or her views consciously or unconsciously after analyzing and comparing the news reports from critical linguistics perspective (p.130). Similar to this view, Xu Tao and Jia Lili (2007) believe that the reported speech is a means of manipulating the audience's ideology by the news media (p. 42). After studying the dynamic intertextuality from the point views of the nominalization, paraphrased quotes and cultural knowledge and so 
on, Liu Lin and Rao Ying (2008) point out that dynamic intertextuality is of great significance to reveal the seemingly objective and impartial subjectivity of news discourse.

\section{The Main Manifestations of InTERTEXTUality in News HeadLINES}

Intertextuality can be divided into two categories, which are specific intertextualiy and generic intertextuality. The former refers to there is others' discourse that can find a specific source in the discourse. The latter refers to different style of discourse, register or genre mix in a discourse. These two types of intertextuality have various manifestations in headlines.

There are four main manifestations of specific intertextuality in the following:

(1) Direct or indirect speech

Example one: 'We are going to recover the people's trust', McCain emphasizes bipartisan ship

Example two: Triumph of Beijing raises bar for London, says IOC chief

(2) Paraphrasing or transforming the fixed phrases or proverb

Example one: Where there is smoke, there is ire, and there is the Mayor's Cash

The headline paraphrases the proverb 'Where there is smoke, there is fire', it changes 'fire' for 'ire' to suggest that smoking is unpopular.

Example two: Shane Warne: More spinned against than spinning

The headline 'More spinned against than spinning.' apparently transforms the fixed phrase 'more sinned against than sinning' in the Shakespeare's "king Lear".

(3) Referring to the historical figures or events

Example one: Winehouse 'bribe plot man' like 'AI Capone'

AI Capone is a leader of a gang that specializes in alcohol smuggling in Chicago during the Alcohol Prohibition. The singer Winehouse's husband was jailed for serious injury, she hired a middleman to threaten the victim and pay him fee to let him go to Spain without appearing in court to testify against her husband. Her trick is tantamount to gang member's trick.

Example two: San Diego now 'Enron by the Sea'

The headline makes full use of the negative connotations of the "Enron event" to send a message to readers that there is a corruption case in San Diego, California now.

(4) Intertexting with films, songs and literary works, etc

Example one: Rule, Britannia, but Maybe Not Over Scotland

The headline borrows the British navy song (Rule, Britannia!).

Example two: Coming in soon: Two theaters near you

The headline is directly based on the 1999 American romantic comedy "Coming soon." It reports two new cinemas to be built.

The main manifestations of generic intertextuality:

(1) The mixed use of words of different styles

Example: Neighbours Kick Up Stink in Court Over Pot-bellied Pig Called Flossy

From the example, we can see that 'kick up' is a kind of colloquial style, and 'stink' is slang that means 'intense complainment'. Both of them are mixed with other words of form style to constitute generic intertextuality.

(2) The headline with linguistic forms and structures of other literary styles

Example: The ice will be nice, but for now, concrete must suffice

The headline is typical poetry language that has a strong rhythmic structure of poetry, which reads like a poem. Naturally, thus it evokes the reader's association of the norms of genre of poetry.

\section{The Pragmatic Functions of Intertextual English News Headlines}

Headline is an inseparable component of news, which integrates the functions of providing information, attracting attention, commenting, touching upon people and having conversation with people from the perspective of pragmatic functions. Intertextuality plays an important role in realizing these functions as an important feature of news headlines.

\section{A. Reflecting the Reliability and Authority of Information}

It is the minimum professional ethic and norm for those who engage in news media industry to reflect the objectivity and veracity of news discourse that is the reflection the credibility of news discourse. Moreover, the authority of the report embodies the quality of the news medium, which can enhance the persuasiveness of news. Employing the reported speech heavily is a common strategy for news media to reflect the reliability and authority of information source of headlines. In order to add authenticity of the news report and show the objectivity of the report, the reporter quotes a great deal of other's discourse. In this way, the news reporter can assure readers that there was no personal opinion in news discourse (Xin Bin, 2005, p.75-105). Besides, because the direct speech is usually from the parties, the insiders, or the authorities, it is often to be believed by the addressees.

Therefore, employing the reported speech plays an important role in enhancing the authority of discourse. Meanwhile, 
The names or titles of those who is authoritative, famous, charming and influential in the narrative clause of the headlines have great appraisal value for the readers and produce lots of contextual effect, which co-occur with the reported speech in the headlines, producing a "magnet" effect visually and arouses reading appeal of the readers.

Example one: Brown warns Iran to end "totally abhorrent" threat to destroy Israel

Example two: Coal-fired power station will lock UK into a high-emission future, say MPS

"Brown" and "MPs" in the above examples represents Britain government. They make the country's foreign policy and domestic industrial policy. Therefore, there is no doubt about the authority of their discourse. Naturally, people, especially those who care about Iran, the environmental protection and the Coal-fired power industry do not miss them.

\section{B. Terse Form But Rich Connotation}

English news headlines generally follow the three principles of "ABC", that is, the content should be accurate, the text should be brief, and the structure should be clear. The principle of the brief text is consistent with the interests of the news media itself, which expects to carry as much information as possible in each issue. In order to accomplish the goals of meeting different interests and demands of all kinds of readers and expanding circulation, the content of news covers almost every aspect from domestic to international, from politics, economy, military, sports to marriage, family, fashion nowadays.

However, people's reading is selective. In face of network news with huge amounts of information and newspapers with more and more layouts, people often search and position headlines that he or she is interested in by scanning, then decide how to read the content of the article. Most readers read news only by reading its headlines. As a result, the media preferred the headlines with terse form or ones compressing and abstracted the content of news discourse.

Example one: The global warming battle: united we stand, divided we fall

"United we stand, divided we fall" is from Aesop's fables, which has been used by many famous people. The headline sends a clear message to the reader by referring to it directly, that is, the problem of global warming can only be solved by means of all countries taking concerted action all over the world. Intertextuality makes the form of the headline concise and the content of the headline clear.

Meanwhile, the headlines with the heavy feel are good ones. The layers of meaning of the headlines cannot be identified at a glance, but we will discover more and more new meaning when we peel them it off one layer at a time like literary baklava, the kind of headline is considered a good one. In other words, the good headlines should meet these three requirements: Firstly, the information content should be rich. Secondly, the connotation should not be shallow. Lastly, the artistry should be high, not boring (Xue Zhongjun, 2005, p. 304-305). The three aspects are also the advantages of intertextual news headlines. There are a great number of intertextuality materials are closely related to literature, music, history and other cultures. Concise language carries rich cultural information and connotation. For example, the common form of the intertextual headlines: allusion, "the environment, motivation, and character relationships of historical events already are contained in allusions, brief suggestions replace the unnecessary details, explanations and evaluations (Ji Guangmao, 1998, p. 75).

Example two: Australia and US 'Bonnie and Clyde' of global warming: Gore

The headline is about the commentary on the United States and Australia that did not sign the Kyoto protocol by environmental activists and American former vice President Gore in November 2005. Bonnie and Clyde are a pair of 'male and female thieves' in the middle of the United States during The Depression. They robbed banks, killed police, and are known as the Romeo and Juliet who fled. Their stories were not only filmed, but were also composed by musicians from the United States, Britain, Russia and Germany. People are familiar with the movies and songs about them. 'Bonnie and Clyde' of the headline makes readers' imagine space extends to prototype stories of the allusion and its related films and music works, naturally make the headline become the compound of language that not only is full of visual and auditory imagine, but also carries rich connotation. It is obvious in the headline that the relationship between the United States and Australia in the global climate crisis is compared to 'Bonnie and Clyde', which is meant to show that they worked hand in glove with each other in reducing emissions.

Example three: $\mathrm{Ob}$ the Builder

The article is about the promise of the US presidential candidate Barack Obama in August 28, 2008 presidential campaign including fixing the broken politics in Washington, solving the problem of discrimination, reducing taxes and coordinating social relationships in the United States. 'Ob' of the headline refers to Barack Obama. The headline imitates "Bob the Builder," the name of a British children's TV series. "Bob the Builder" is a building contractor in the play. He asked "Can we fix it?" when facing trouble, and he always received the reply "Yes, we can". The play highlights the theme of resolving contradictions and conflicts, cooperation and socialization. There are only three words in the title, but it is the semantic tensity that is formed by the intertextual headlines pointing to intertextuality archetype texts, which makes the theme of drama give the headline, which greatly enriches the connotation and expression of language.

\section{Attracting the Attentions of Readers}

The enjoyment of news is an important factor for the value of news from the perspective of journalism. There are three functions of headlines in the news discourse: promoting article, outlining content and beautifying layout. As the old saying goes, the first thing to read a book is to read its cover, the first thing to read news is to read its headline. 
Whether or not news headlines can capture readers' wandering eyes and arouse the interest of readers is the key to prompt the articles successfully.

There are three factors to attract the attentions of readers including the information, enjoyment and poetry nature of headlines. From the reader's psychological point of view, they live in a society in which the pace of life is fast and the work pressure is great, so they hope to find some reading material that can temporarily relax their body and mind when they are free. It will undoubtedly catch the reader's eyes and stimulate his desire to read if the headline is full of enjoyment and the sense of humor.

Example one: Axis of feeble

The closing of the Bush-Blair era

Both Mr Bush and Mr Blair are the leaders of countries who are about to end their tenure, so their alliance is a weak union. According to "Axis of evil," Bush created a new "Axis of feeble" to describe the current situation of "lame-duck", making the headline humorous.

Example two: Football: On a Whinge and a Prayer

The second half of the headline 'On a Whinge and a Prayer' originates from the American Second world war song Coming in on a wing and a prayer, which sings a pilot who tried to land a wounded plane safely. It reveal the fact that the Scottish football team still managed to win in the end in spite of question and discontent of people at home by replacing the 'wing' with 'whinge'.

Humor has its internal psychological mechanism. As a kind of ideographic symbol system that is restricted by a variety of conventions, the collocation and arrangement of the words and semantic expression and understanding are not only restricted by the rules of the language system, but also by the common conventions in language user community (Zhu Ximing, 2002, p. 119). These constraints enable the language user to have mental-set of specific language patterns. Once it is broken, which can make the psychological anticipation empty, but humor will be perceived with the unexpected discovery. Intertextual headlines usually transform the form or structure of intextual prototype text moderately, change the original reference object or concept, which make the collocation of language or the context unconventional. Therefore, the mental-set of the readers is broken, which achieve the purpose of humor.

When readers see the 'axis of ' in example one, their anticipations for the subsequent language is 'evil'. The presence of 'feeble' makes reader's anticipation empty. However, the hint of subtitle makes readers understand the meaning of the headline immediately. Naturally, they have the desire to read spontaneously. In example two, 'wing' sounds similar to ' whinge,' but the visual difference clearly tells the readers that the text of the headline is different from the original text. It is the difference of collocation that is the basis of humor. Besides, it is the previous knowledge that is evoked by intertext that makes humor possible.

\section{Producing Specific Rhetorical Effects}

The successful headlines are not only concise and compelling, but also palyful sometimes. In order to make the headline vivid and novel and artistic, editors often use the intertextuality to create the rhetorical effects like pun, irony and parody and so on. Pun is one of the rhetorical devices used by the English media. As part of British culture, it is even more popular in the headlines of British media.

Example one: Officials say atoll do nicely

The'atoll' in the headline means "coral island" and its paronomasia is "that will do", so another meaning of the headline is "Officials say that will do nicely". "That will do nicely." is a British television advertisement, which tells a story of When a customer asked if he could pay with a credit card, the salesperson replied, "Yes, that will do nicely." The article is about a fraudulent sale of small islands in the Pacific, so the implication of the headline is that officials tell potential island buyers to say "welcome to buy". Intertextuality established a referential connection between advertising text and headline text, creating double context, a necessary condition of pun, through which the ugly face of government officials who are money-mad and dishonest politician are portrayed with sharp, sarcastic wit.

Example two: George Orwell, Big Brother is Watching Your House

Big Brother is a totalitarian in the British writer George Orwell's satirical novel of "1984". In his country where everyone is completely monitored by the ruler's television screen, the phrase "Big Brother is watching you" is a constant reminder for people. George Orwell's home and nearby area had 60 surveillance cameras, which was a great irony for him. But behind the irony, there is a strong dissatisfaction with the surveillance. The intertextuality makes the headline achieve a better implicit ironic effect.

Irony is one of the common rhetoric devices of the headline, although more and more used by some second-rate newspapers or websites. According to the research, we can found that the serious mainstream websites also employ 2 to 3 ironic headlines per week on average. Even serious newspapers and websites use a lot of irony during the special period such as political conflict or scandal, because the message itself is shocking and the irony explodes. In addition, irony can disguise the real intention, so that the cynicism is implicit in the lines.

\section{E. Closing the Distance with Readers and Creating Relaxing and Atmosphere}

Different genres have different meaning potential, so construct different subject positions and reading positions usually contain the different status types of participants and communicative intention of discourse subjects. Stylistic changes often produce wonderful linguistic effects. One important function of news headlines is the function of 
dialogue. Dialogue first requires equality between the two sides, and the use of colloquial language is an effective way to achieve equal communication with readers.

Example one: Doody calls

This is the winning headline of the 2004 headline contest of the American newspaper editors' association. The article is about a man named Ken Simmons who works on dog poop. Doody is a child's term for "feces". The use of "Doody" makes the article have the feature of the daily conversations. The fusion of colloquial and journalism effectively creates a relaxing and lively atmosphere of communication, which enhances the affinity and appeal of the headline.

Example two: Pregnant or not: A hunka, hunka burning question for Lisa Maire Presley

The report was based on the fact that Lisa Maire Presley, the only daughter of Elvis Presley, was pregnant according to her clothes. "A hunka, hunka'm burning question" of the headline constitutes the manifest intertextuality with the lyric of Elvis Presley's song (I'm just a hunka hunka'm love). At the same time, It also aroused the readers' association with the related features and norms (constitute intertextuality) of the genre. Ordinary people read entertainment news, is a kind of leisure and recreation. The reporter integrates the relaxing song into the serious headline, which enables readers to fly on the wings of imagination and to feel ease and pleasure brought by the music.

\section{CONCLUSIONS}

Intertextuality is not only the main feature of news discourse, but also an important feature of news discourse headlines. Some people think that the fierce competition between modern news media is, in a sense, the high level of competition in making news headlines. Intertextuality has a place in this competition and become a major feature of English news headlines in English. The main reason is that the intertextuality can increase the information content of news headlines, enrich the content, make the way of expression novel and lively, and make the headlines more readable and appealing. As an important medium for external publicity, domestic English newspapers, especially for overseas readers. It is necessary for them to learn the methods and skills of foreign news media in writing news headlines, make full use of the unique function and effect of intertextuality in the headlines, and enhance the artistry and expression of the headlines. Finally, they should create conditions for achieving external publicity efficiently by creating high quality news headlines and improving the competition of domestic English newspapers.

\section{REFERENCES}

[1] Fowler, R. (1991). Language in the News: Discourse and Ideology in the Press. New York: Routledge.

[2] Goatly, A. (2000). Critical Reading and Writing: An Introductory Coursebook. London: Routledge.

[3] Ji Guangmao. (1998). Poetic Tradition in the View of Metaphor. Beijing: Higher Education Press.

[4] Jiao Shumin \& Lu Puling. (2009). The Influence of Network News Intertextual Narrative on Newspaper News Narrative. Contemporary Communications. 3, 102-103.

[5] Kristeva. (1986). The Kristeva Reader. Oxford: Basil Black-well.

[6] Liu Lin \& Rao Ying. (2008). Analysis of Intertextuality in English News Headlines. Journal of Xi'an International Studies University, 16,10-14.

[7] Van DiJk. (2003). News as Discourse. Beijing: HuaXia Press.

[8] Xin Bin. (2005). Critical Linguistics: Theory and Application. Shanghai: Shanghai Foreign Language Education Press.

[9] Xu Tao \& Jia Lili. (2007). Ideology behind The Reported Speech. Research in Foreign Language and Literature, 7, 42-50.

[10] Xue Zhongjun. (2005). Comparison between China and America News Media. Shanghai: Fudan University Press.

[11] Zhu Ximing. (2002). Psychological Mechanism and Cognitive Basis of Conversational Humor. TongJi University Journal, 4,120-122.

Qin Xie was born in Lin Fen, China in 1992. Now, she is a linguistic postgraduate, studying at Shanxi Normal University. She has been a teacher at a junior high school in 2015. Her research interests include critical discourse analysis and second language acquisition. 